\title{
Criterios para el Diagnóstico Tratamiento de la Toxoplasmosis
}

\author{
Dr. Alberto Duarte Contreras, M.D.* \\ Clara Inés Duarte Barreto **
}

La Toxoplasmosis es una zoonosis producida por un esporozoario del grupo de los coccídeos, el Toxoplasma Gondii, parásito intracelular que se encuentra ampliamente distribuido en un gran número de animales de sangre caliente, incluido el hombre. Fue descubierto por Nicolle y Manceau en 1909. Colombia es pionera en el estudio de la toxoplasmosis a nivel americano $(23,29)$.

El Toxoplasma cumple su ciclo biológico en gatos $y$ presenta dos fases: una proliferativa y quística y otra intraepitelial. La primera se desarrolla en cualquier célula de mamíferos y aves, excepto en los eritrocitos no nucleados y se comporta como patógeno intracelular obligado. La intraepitelial se adelanta en el intestino, preferencialmente en el íleo del gato, huésped definitivo, quien lo adquiere por sus costumbres carnívoras; en el íleo se multiplica y forma quistes inmaduros $u$ ooquistes que se eliminan por las heces, los que en condiciones apropiadas siguen su evolución y esporulan haciéndose infectantes; estos ooquistes son ingeridos

\footnotetext{
* Médico Jefe de la Consulta de Ginecología Pediátrica de la Clínica Infantil del Hospital San Juan de Dios. Cúcuta.

* Bacterióloga y Laboratorista Clínico, egresada de la Universidad Javeriana.
}

de manera directa o indirecta por una gran cantidad de huéspedes.

El hombre es huésped intermediario y se infecta al ingerir formas quísticas en carnes insuficientemente cocidas (de cerdo, pollo, cordero, res), u ooquistes que pululan por millones en las heces de gatos infectados. $(2,7,8)$.

Diferentes encuestas serológicas demuestran que es la zoonosis parasitaria más ampliamente difundida por el mundo: más del $40 \%$ de la humanidad está parasitada, $(9,25)$. En Colombia la población parasitada constituye el $47.1 \%$ y en nuestro Departamento, Norte de Santander el $56.8 \%$ (14).

La prevalencia de infección es mayor a medida que aumenta la edad. Así, en menores de 10 años la tasa de incidencia es de $32 \%$ y en mayores de 60 años alcanza al $65.3 \%$. La diferencia en la presencia de infección entre hombres y mujeres no es significativa desde el punto de vista estadístico. No obstante el altísimo porcentaje de incidencia de infección, es muy baja la morbi mortalidad, lo que indica que la toxoplasmosis es asintomática en la mayoría de los casos.

La Toxoplasmosis puede ser:
1. Adquirida
2. Congénita 


\section{TOXOPLASMOSIS ADQUIRIDA}

La infección toxoplasmósica adquirida se inicia en cualquier momento después del nacimiento y ordinariamente pasa inadvertida. En oportunidades se inicia con un cuadro clínico variable leve, casi inaparente, muy similar al de la mononucleosis infecciosa, con fiebre, exantema y mialgias para presentar luego varias formas: la más frecuente se manifiesta por linfadenopatías periféricas, diseminadas o localizadas, de predominio cervical; la miocarditis, la neumonitis, la coriorretinitis y la iridociclitis son menos frecuentes; es muy raro el síndrome encefálico con convulsiones y meningismo, con serio compromiso del sistema nervioso central, casi siempre mortal $(4,6,12$, 16).

\section{TOXOPLASMOSIS CONGENITA}

La transmisión congénita es el aspecto más importante de la infección humana y la madre es el factor directo; en este problema debemos centrar toda nuestra atención. (22,31).

Para que la infección toxoplásmica sea considerada como congénita es indispensable que la madre haya adquirido la infección durante el embarazo que cursa. $\mathrm{Si}$ la mujer adquirió la toxoplasmosis en un embarazo anterior y dio a luz un hijo infectado o no infectado, en un nuevo embarazo JAMAS DARA A LUZ UN NIÑO INFECTADO.

Cuando una mujer no infectada inicia la toxoplasmosis en cualquier momento del embarazo que cursa, el producto puede adquirir la toxoplasmosis congénita $y$ nacer infectado o no infectado.

En nuestro medio el $1 \%$ de las gestantes tienen alto riesgo de dar a luz un recién nacido con toxoplasmosis. La incidencia mundial de toxoplasmosis congénita es en la actualidad de 1 por 8.500 nacimientos. (13).
Cuando la mujer adquiere la infección toxoplásmica durante la gestación, el embarazo puede terminar en aborto, en parto prematuro o en parto a término, con recién nacido infectado o rio infectado o con mortinato.

Desmonts y Couvreur demostraron que cuando la madre adquiere la infección durante el embarazo, aproximadamente el $50 \%$ de los fetos se infectan pero no enferman $y$ nacen sanos, sin secuelas de la enfermedad y sólamente menos del $1 \%$ nacen enfermos con manifestaciones toxoplásmicas tales como coriorretinitis, hépato-esplenomegalia, microcefalia, hidrocefalia con macrocefalia, calcificaciones difusas intracerebrales, etc. $(5,12,20,26)$.

Si la gestante adquiere la toxoplasmosis en el primer trimestre del embarazo, el daño en el producto es mayor ya que el sistema nervioso central apenas se está organizando: casi todos estos embriones mueren y son abortados, hecho que puede deberse a la acción directa del parásito o a trastornos nutritivos que impiden el desarrollo normal del embrión; por ello en este caso la infección congénita es poco común. Los que sobrevivan nacerán con coriorretinitis o con cualquier otro daño oftálmico, reducción de la capacidad de aprendizaje u otras manifestaciones de deficiencia del sistema nervioso central o con una lesión latente asintomática que puede hacerse presente años después. Por este motivo, cuando se comprueba que un recién nacido está infectado, así sea asintomáti$\mathrm{co}$, se debe tratar ya que puede tener una coriorretinitis congénita de manifestación tardía. $(10,30,34)$.

Cuando la infección se adquiere en el segundo trimestre puede ocasionar la "triada de Sabin": hidrocefalia, ceguera y un grado variable de lesiones neurológicas menores.

Cuando la infección se inicia a finales del segundo o en el tercer trimestre, es 
frecuente la toxoplasmosis congénita, hasta en el $65 \%$, pero ordinariamente asintomática, si bien puede presentarse la forma neurológica activa o la forma septicémica (23).

El toxoplasma atraviesa la barrera placentaria, pero este paso transplacentario está sujeto a factores aún no bien conocidos, entre otros, lesiones tisulares (como alteraciones de la permeabilidad), o trastornos hormonales o enzimáticos $(1,28)$.

Es posible que durante el embarazo se reactive una toxoplasmosis, pero no se ha descrito el primer caso de toxoplasmosis congénita por reactivación.

\section{EVOLUCION}

La infección toxoplásmica presenta tres etapas bien definidas:

1. La contaminación que se hace por vía oral al ingerir formas quísticas: va seguida de multiplicación de formas libres que circulan a sus anchas y van a refugiarse en las células retículo endoteliales;

2. Dos semanas después de adquirida la infección se inicia la producción de anticuerpos y empiezan a escasear las formas libres, menos en el ojo y en el cerebro, órganos que poseen pocos anticuerpos por carecer de elementos linfoides $(30,33)$;

3. En una etapa posterior o fase crónica, los parásitos no salen de las células del retículo endotelio y forman seudoquistes repartidos por todo el organismo; en esta forma el toxoplasma permanece indefinidamente en los tejidos pero no es agresivo debido a la inmunidad celular. Se ha demostrado que todos los tejidos del aparato genital femenino, a excepción del folículo y del epitelio cilíndrico de la trompa, son suceptibles a la infección toxoplásmica, y en todos ellos, incluyendo el endometrio, se pueden encontrar las formas quísticas.

\section{PRODUCCION DE ANTICUERPOS}

Aproximadamente a las dos semanas de haberse iniciado la infección toxoplásmica aparece en la madre una respuesta inmune: la formación de anticuerpos (Ac.) antitoxoplasma tipo $\lg G$ e $\lg \mathrm{M}$.

Normalmente los títulos de estos anticuerpos aumentan en forma gradual y los IgG se estabilizan 6 a 8 semanas después de iniciada la infección, a niveles altos, iguales o mayores a 1:1024 (mil veinticuatro por dilución) y permanecen altos, a títulos iguales o mayores a 1 : 1024, por unos 6 meses para luego descender y conservar niveles bajos por tiempo indefinido. Los anticuerpos tipo IgM descienden a los 4 meses. (21). Cuando se constituye la respuesta inmune celular o humoral, sólamente pueden sobrevivir los toxoplasmas enquistados. (3). Para que los anticuerpos sean sintetizados es indispensable la presencia de un sistema inmunológico intacto, sin inmuno-supresión. Por ello el feto en desarrollo y el huésped anciano o el comprometiclo en su sistema inmunitario son los más vulnerables a la expresión patológica de la infección masiva que causa enquistamiento en el ojo $\mathrm{y}$ en el cerebro.

Los anticuerpos se sintetizan en abundancia por las células linfoides dondequiera que ellas se hallen. El toxoplasma puede alterar los macrófagos $y$ entonces la información inmune es deficiente y como respuesta habrá una deficiencia inmunológica celular.

Los anticuerpos IqG maternos atraviesan libremente la placenta del tercero o cuarto mes de la gestación y por transporte activo selectivo puede encontrarse una mayor concentración de estas inmu- 
noglobulinas en la sangre fetal que en la materna. La placenta hace un paso activo y pasivo de las inmunoglobulinas. (22).

En la mayor parte de especies animales se elaboran anticuerpos en el feto, pero son escasos o casi nulos, hecho que obedece a dos razones: 1) por inmadurez inmunológica, y 2) porque la exposición a estímulos de antígenos extraños se ve limitada por la barrera de las membranas que revisten al feto. Cuando el embrión o el feto se enfrentan a un estímulo antigénico potente, los principales anticuerpos que se forman son del tipo $\operatorname{lgM}$, pero estos anticuerpos no son suficientes para protegerle en presencia de cifras altas de ant ígenos. Los antígenos IgM no atraviesan en cantidad importante la placenta humana. Después de la semana 20 de gestación el sistema inmunológico está maduro y el feto puede producir ya anticuerpos si se somete a estímulos intensos de tipo infeccioso, pero no se sabe si esta reacción aumenta la protección brindada por los anticuerpos maternos. Ante la infección toxoplásmica el feto produce anticuerpos específicos y son principalmente del tipo IgM; se forman fácilmente y con frecuencia se les encuentra en pequeña concentración en el cordón umbilical. La concentración apreciable de IgG o de IgM en la sangre del cordón umbilical/indica infección toxoplásmica reciente.

Se tienen pocos datos acerca de la formación de anticuerpos IgG por el feto y su posible producción es difícil de medir porque son disimulados por los anticuerpos lgG maternos que atraviesan la placenta libremente.

"Datos recientes hacen pensar que existe una barrera hematoencefálica constitu ída por los caracteres estructurales peculiares de los capilares del sistema nervioso central". Los plasmocitos se colocan en la submucosa de los epitelios. "Las células endoteliales son aplanadas y se superponen unas a otras; además, hay prolongaciones de las células de neuro- glia íntimamente unidas a las células endoteliales, separadas de las mismas por un espacio ocupado por sustancia amorfa de cemento. En estado normal la barrera hematoencefálica parece ser impermeable a todos los grupos de anticuerpos pero en oportunidades puede haber paso de anticuerpos séricos a través de la barrera hematoencefálica dañada". (33). En estado normal en el neonato la formación de anticuerpos $\lg M$ comienza al nacer. A los cuatro meses han desaparecido los anticuerpos $\lg \mathrm{G}$ recibidos de la madre y se inicia la producción de cantidades importantes de anticuerpos IgG por el niño. La aparición de anticuerpos en los prematuros es un poco mas tardía al compararlos con los nacidos a término.

\section{DIAGNOSTICO}

El diagnóstico de la infección toxoplásmica se hace por la presencia de anticuerpos específicos, los que se investigan casi exclusivamente por métodos serológicos; así se emplean las siguientes pruebas: (15).

1. Sabin-Feldman o Test de coloración (Dye Test): es una prueba de lisis de los toxoplasmas o de neutralización in vitro o de exclusión del colorante de Sabin-Feldman. Se hace positiva 10 a 14 días después de la infección y permanece positiva por toda la vida. Se responde en U.I. En la actualidad es poco usada por el peligro que corren los Laboratoristas de contraer una infección masiva, pues requiere toxoplasma vivos.

2. Intradermo reacción con toxoplasma o Prueba cutánea de Frankel: no da respuesta cuantitativa. Se usa en investigaciones epidemiológicas. Se interpreta igual que la tuberculina.

3. Hemaglutinación indirecta. Exige el tratamiento de eritrocitos de cordero por el ácido tánico y por el antígeno proveniente de toxoplasmas vivos. Se 
hace positiva después de dos a tres meses de producida la infección. Requiere trabajar en medio muy estéril.

4. Fijación del complemento. El resultado depende del extracto antigénico utilizado: si se usan antígenos "ligeros" de citoplasma, la reacción se positiviza más tardíamente y se negativiza más rápido que en la prueba de Sabin. Es una prueba muy específica pero no muy sensible.

5. Aglutinación directa. Es un examen rápido que se lee macroscópicamente.

6. Inhibición de la hemaglutinación. Es un método particularmente sensible que puede servir para el descubrimiento de los anticuerpos de la cámara anterior del ojo.

7. Reacción de aglutinación de partículas inertes, Látex, y de hemo aglutinación pasiva. Depende del extracto antigénico utilizado para sensibilizar las partículas de Látex o los hematíes.

8. Inmuno fluorescencia indirecta. IFI. Es el método usado en la actualidad. (17).

\section{Otros.}

La inmunofluorescencia indirecta es una prueba mucho más simple que la prueba de lisis. Sucesivamente se hace actuar sobre una extensión fija de toxoplasmas el suero sospechoso y además un conjugado fluorescente de antiglobulinas gama humanas en el que se ha verificado la ausencia de anticuerpos antitoxoplásmicos.

$\mathrm{Si}$ el suero es positivo, los toxoplasmas son fluorescentes a la luz ultravioleta. Los resultados se expresan por dilución. $\mathrm{Si}$ los títulos se expresan en unidades internacionales, U.I., por comparación con el suero patrón de la OMS, los resultados de la inmunofluorescencia indirecta son comparables con los de la prueba de lisis.

La Prueba de Remington es una reacción de inmunofluorescencia indirecta que utiliza un conjunto fluorescente an- ti IgM humana, lo cual pone de manifiesto los anticuerpos antitoxoplásmicos tipo IgM. Como estos anticuerpos son de aparición precoz y desaparecen habitualmente antes de cuatro meses, la prueba de Remington no es positiva más que en la toxoplasmosis reciente.

Sabiendo que ocho semanas después del comienzo de la infección los títulos lgG pueden llegar a un máximo y estabilizarse, entendemos el por qué los títulos de fijación de complemento y hemoaglutinación no pueden utilizarse como parámetro de relación a la época de infección y tiempo de concepción, puesto que estos títulos permanecen altos hasta ocho meses después de iniciada la infección.

\section{INTERPRETACION DE LA IFI.}

$\mathrm{Si}$ a una embarazada le encontramos títulos de anticuerpos antitoxoplasma tipo IgG iguales o superiores a 1:1024 se deben buscar anticuerpos antitoxoplasma tipo IgM: de ser positivos a cualquier dilución, estamos ante una toxoplasmosis recientemente adquirida. (27).

Si no tenemos a mano la prueba serológica para detectar anticuerpos antitoxoplasma $\lg M$, se hará una nueva titulación de anticuerpos IgG dos o tres semanas más tarde. $\mathrm{Si}$ los títulos se encuentran aumentados en dos o tres diluciones, la paciente presenta una toxoplasmosis recientemente adquirida.

Cuando los anticuerpos antitoxoplasma lgG, iguales o superiores a 1:1024 y, o permanecen estables a las tres semanas, o con títulos negativos de $\lg M$, la infección fue adquirida antes del embarazo.

Pero si los anticuerpos antitoxoplasma $\lg \mathrm{G}$, iguales o mayores a 1:1024 permanecen estables a las tres semanas, pero con títulos positivos de $\lg \mathrm{M}$, la infección fue adquirida cuatro a ocho semanas antes de la obtención del suero. 
Cuando el suero ha sido tomado de la madre en los dos primeros meses del embarazo y se encuentran títulos de anticuerpos antitoxoplasma iguales o mayores a 1:1024, que permanecen estables a las tres semanas, el embrión no está en riesgo: la toxoplasmosis fue adquirida antes del embarazo.

$\mathrm{Si}$ una embarazada asintomática presenta al final del segundo o en el tercer trimestre títulos de anticuerpos antitoxoplásmicos lgG 1:1024, con un aumento no significativo en titulaciones posteriores o con un título $\lg M$ negativo, es imposible detectar si la infección ocurrió antes o después de la concepción. Lo importante en este caso es definir el tratamiento.

El diagnóstico de toxoplasmosis aguda en el neonato puede hacerse por la persistencia de títulos altos de $\lg$, o cuando éstos van en aumento, o cuando los títulos IgM son positivos a cualquier dilución así no haya sintomatología y aún en ausencia de daño placentario.

El Centro de Control de Enfermedades, CDS, da unas normas, a nuestra manera de ver de gran utilidad para el médico práctico, sobre cómo debe interpretar los resultados de la investigación de anticuerpos antitoxoplasma tipo $\lg G$ por la técnica de inmunofluorescencia indirecta, IFI. (24). Ellas son:

\section{Títulos de 1:16 a 1:64}

Más del $30 \%$ de la población aparentemente sana se encuentra dentro de esta categoría. Indican una exposición anterior: hay una toxoplasmosis latente o crónica, o una infección reciente con iniciación en el aumento de los títulos.

\section{Títulos de 1:256:}

Más del $10 \%$ de la población aparentemente sana se ubica dentro de esta categoría. Indica que hay una exposición un poco menos reciente $y$ tal vez una infección en desarrollo. Es un indicio para alertar al médico.

\section{Títulos de 1:1024 o más:}

Es un título indicativo de infección aguda, pero un solo examen no hace el diagnóstico; un aumento significativo en el título en un segundo examen da seguridad diagnóstica. Lo que significa que pacientes embarazadas con títulos estables de 1:1024 o con IgM negativos, no se tratan; si a las dos o tres semanas suben dos o tres veces los títulos IgG, se deben tratar.

De acuerdo a estos conocimientos, existen algunas guías que relacionan la positividad de anticuerpos antitoxoplasma IgG prenatales e infección congénita (Cuadro 1).

\section{Cuadro 1}

\begin{tabular}{|ccc|}
\hline Ac. tipo IgG & $\begin{array}{c}\text { Ac. tipo } \\
\text { IgM }\end{array}$ & $\begin{array}{c}\text { Infección } \\
\text { congénita }\end{array}$ \\
\hline $1: 1024$ a $1: 2048$ & positivo & frecuente \\
$1: 1024$ a $1: 2048$ & negativo & $\begin{array}{c}\text { rara vez } \\
\text { presente }\end{array}$ \\
$1: 2048$ a $1: 4096$ & negativo & $\begin{array}{c}\text { relativamente } \\
\text { frecuente }\end{array}$ \\
menor de 1:1024 & positivo & $\begin{array}{c}\text { posible } \\
\text { excluída }\end{array}$ \\
\hline
\end{tabular}

\section{TRATAMIENTO}

El tratamiento se debe instaurar cuando hay:

1) Infección reciente sintomática

2. Infección ocular activa

3. Embarazadas cuyos títulos aumenten tres o más veces.

4. Neonatos con clínica de enfermedad o con títulos de $\lg$ en aumento, o de IgM positivos.

El tratamiento es relativo en: 
1. Abortadoras habituales con títulos anticuerpos antitoxoplasma IgG mayores de 1:256.

2. En las reactivaciones.

\section{CONCLUSIONES}

A toda embarazada se le deben buscar títulos de anticuerpos antitoxoplasma tipo IgG.

De ser positivos, investigar si la infección toxoplásmica ha sido adquirida durante el embarazo que cursa o antes de la concepción.

$\mathrm{Si}$ la infección fue adquirida en el embarazo en curso, se debe iniciar de inmediato el tratamiento. Pero si fue adquirida antes de la concepción no se necesita tratamiento ya que el embrión o el feto no corren peligro alguno en este caso. Para que haya toxoplasmosis congénita es indispensable que la infección haya sido adquirida durante el embarazo en curso. La tercera parte de los productos de madre que ha adquirido la enfermedad durante el embarazo se infecta pero no enferma. Toda placenta de madre que ha adquirido la toxoplasmosis durante el embarazo que acaba de terminar se debe enviar a estudio histopatológico.

La puesta en evidencia de anticuerpos antitoxoplásmicos durante un embarazo o fuera de él, ha dado lugar a muchos errores de interpretación y a

\section{BIBLIOGRAFIA}

1. APT, W. Transmisión congénita de protozoos parásitus. Bol. Of. Sanitaria Panam. junio: 517, 1972.

2. BENENSON, M.W. et alt. Oocyst transmitted toxoplasmosis associated with ingestion of contaminated water. N. Engl. Med. 307: 666, 1982.

3. BERGOGLIO, R.M. y DAIN, E.A.L. Síndromes clínico infectológico. Pág. 166, 1977. tratamientos "profilácticos" inoportunos e incluso peligrosos.

La mujer no embarazada con títulos de anticuerpos antitoxoplasma IgG positivos, adquirió la toxoplasmosis tiempo atraś, está vacunada, y no requiere tratamiento alguno, salvo en casos de toxoplasmosis sintomática como lesiones oculares. El niño nacido de madre con toxoplasmosis adquirida durante el embarazo, se debe tratar sólo cuando nace con lesiones o secuelas, o cuando los títulos de $\operatorname{lgG}$ van en aumento o los anticuerpos IgM son positivos a cualquier título, haya o nó lesiones aparentes. A estos niños se les debe hacer un seguimiento con investigación de anticuerpos antitoxoplasma IgG siquiera por dos años puesto que hay coriorretinitis congénitas de manifestación tardía.

\section{RESUMEN}

Se hace un repaso sobre lo que es la infección toxoplásmica, el comportamiento del toxoplasma en el organismo y los mecanismos de defensa. Se estudia la manera de diagnosticar la toxoplasmosis congénita. Se dan conclusiones.

\section{RESUME}

L'auteur passe en revue l'infection toxoplasmique, la conduite du toxoplasme dans l'organisme et les mécanismes de défense. Par la suite on discute quoi faire pour diagnostiquer la toxoplasmose congénitale. On formule les conclusions.

4. BOTERO, D. y cols. Estudio sobre la toxoplasmosis hurnana en Colombia. Antioquia Médica. 15: 325, 1965.

5. DESMONTS, G. and COUVEUR, J. Congenital toxoplasmosis: a prospective study of 378 pregnancies. N. Engl. J. Med. 290: 1110, 1974.

6. DUARTE-CONTRERAS, A., BUSTAMANTE, A.G., LUZARDO, M.L.F. y PALAU, C. 
M.J. Toxoplasmosis y embarazo. Rev. Colomb. Obstet. Gin. 21: 95, 1970.

7. FRENKEL, J.K., DUBEY, J.P. and MILLER, N.L. Toxoplasma Gondii in cells: fecal stages identified as coccidian oocysts. Science. 167: 893, 1970.

8. FRENKEL, J.K. Avances en Toxoplasmosis. Rev. Latinoam. Patología. 10: 5, 1971.

9. FRENKEL, J.K. y RUIZ, A. Toxoplasmosis humana. Acta Médica Costarricense. 16: 5, 1973.

10. FRENKEL, J.K. Congenital Toxoplasmosis: prevention or palliation Am. J. Obstet. Gynecol. 141: 359, 1981.

11. GIORGINO, FL. et alt. Toxoplasmosis and habitual abortion. Our experience. Clin. Exp. Obstet. Gynecol. 8: 132, 1981.

12. HARRISON, T.R. y FELDMAN. H.A. Toxoplasmosis. En "Medicina Interna". Ed. La Prensa Médica Mexicana, México, 1979, Pág. 1278.

13. HUNTER, K. et alt. Prenatal screening of prenatal women for infections caused by cytomegalovirus, Epstein-Barr virus, herpes virus, rubella and Toxoplasma Gondii. Am. J. Obstet. Gynecol. 145: 269, 1983.

14. JULIAO, O., CORREDOR, A y MORENO. G.S. Toxoplasmosis en Colombia. Estudio Nacional de Salud. Bogotá. enero 1983, Pág. 19.

15. KAMAUN, J.P. Diagnóstico serológico de la toxoplasmosis. En "Guía de exámenes de Laboratorio". Ed. Frajeville. 1981, Pág. 166.

16. KEAN, B.H. Clinical Toxoplasmosis 50 years. Trans. Roy. Soc. Trop. Med. Hyg. 66: 549, 1972.

17. KNIERIM et alt. Practical aspects in the inmuno diagnosis of toxoplasmosis. Bol. Chil. Parasitol. 35: 3, 1980.

18. KUMATE, J. y GUTIERREZ, G. Manual de infectología. Ed. Médicas del Hospital Infantil de México. 6a Ed. México 1978.
19. LEAL, Q.F.J. y cols. Estado de la inmunidad específica frente al síndrome Turch en gestantes colombianas y determinación de población en riesgo. Ed. Artegraf de Occidente. Bogotá, 1983.

20. MOZZICONACCI, P. y cols. Enfermedades infecciosas del niño. Ed. Jins. Barcelona, 1973.

21. NAOT, Y. et alt. Duration of IgG antibodies to toxoplasma gondii after acute acquired toxoplasmosis. Infect. Dis. 145: 770, 1982.

22. PEDERSEN, B.S. Congenital toxoplasmosis. Am. J. Obstet. Gynecol 136: 399, 1980.

23. PLATA, R.E. Estado actual del diagnóstico y tratamiento de la toxoplasmosis. Pediatría, 19: 19, 1982.

24. Public Health. Education and Welfare. C.D. C. Serodiagnosis of: toxoplasmosis, rubella, cytomegalic inclusion disease, herpes simplex. Inmunology Series, No. 5. Procedural Guide. Atlanta, Georgia, 1977.

25. REMINGTON, J.S, et alt. Studies on Toxoplasmosis in El Salvador. Trans Roy. Soc. Trop. Med. Hyg. 64: 252, 1970.

26. REMINGTON, J. and KLEIN, J. Infections diseases of the fetus and newborn infant. Ed. Saunders. Philadelphia, 1976.

27. REMINGTON, J.S., MILLER, M.J. and BROWNLEE, I. IgG antibodies in acute toxoplasmosis: prevalence and significance in acquired cases. J. Lab. Clin. Med. 71: 855, 1968.

28. RESTREPO, I.M. y cols. Toxoplasmosis en el embarazo y su transmisión placentaria. Rev. Colomb. Obstet. Gin. 22: 133, 1971.

29. ROCA, G.M. CAMACHO, G.J. y ESGUERRA, G.G. Un caso de toxoplasmosis congénita. Rev. Colomb. Ped. Puer. 10: 15, 1951.

30. ROLLINS, D.F. et alt. Detection of toxoplasmal antigen and antibody in ocular toxoplasmosis. Arch. Ophtalmol. 101: 455, 1983.

31. RONDANELLI, E.G. et alt. Toxoplasmosis and pregnancy. The prevention of congenital toxoplasmosis. Int. J. Biol. Res. Pregnancy. 2: 104, 1981. 
32. WIESNER J. Toxoplasmosis y gestación Rev. Colomb. Obst. Gin. 34: 127, 1983.

33. WEISER, R.S., MYRVIK, Q.N. y PEARSAL, N.N. Inmunología. Ed. Interamericana S.A. México, 1970.
34. WILSON, C. et alt. Development of adverse sequelae in children born with Subclinical congenital toxoplasma infection. Pediatrics. 66: $767,1980$. 